\title{
Pressupostos das pesquisas em code-switching
}

\author{
Ariela Fátima COMIOTTO (D) \\ Universidade Federal de Santa Catarina (UFSC)
}

\section{RESUMO}

Nesta resenha, abordamos os principais pontos apresentados na conferência Questioning assumptions in code-switching research, ministrada por Margaret Deucher, na data de 8 de julho de 2020, como parte das atividades da Abralin Ao Vivo - Linguists Online. O fenômeno de code-swtching é compreendido como o uso de mais de uma língua em um mesmo enunciado. Em seguida, discute-se como identificá-lo e diferenciá-lo dos empréstimos linguísticos. Por fim, é questionado sobre quais são as evidências nos padrões de CS em comunidades bilíngues, ao que a autora argumenta que é possível que existam regras adquiridas pelas comunidades quanto aos padrões de code-switching.

\section{ABSTRACT}

In this review, we address the main points presented by Margaret Deucher at the conference Questioning assumptions in code-switching research, on July 8, 2020, as part of the activities of Abralin Ao Vivo - Linguists Online. The phenomenon of code-switching is understood as the use of more than one language in the same statement. Then, the means by which code-switching can be identified and differentiated among linguistic bor-

AVALIADO POR

Aline Lorandi

DATAS rowings are discussed. Finally, questions on the evidences in CS norms in bilingual communities are brought to the fore, to which the author argues there may be rules, regarding the code-switching norms, acquired by the communities.

\section{PALAVRAS-CHAVE}

Code-Switching. Bilinguismo. Análise de dados.

\section{KEYWORDS}

Code-Switching; Bilingualism; Data Analysis. 


\section{REVISTA DA ABRALIN}

O tema da alternância de códigos ou o code-switching vem sendo estudado ao longo dos últimos 40 anos. Entretanto ainda há divergências encontradas entre os pesquisadores da área sobre o funcionamento do fenômeno. Pensando em tais implicações, a professora da University of Cambridge e Bangor University, Margaret Deuchar, ministrou uma conferência em 08 de julho de 2020, intitulada Questioning assumptions in code-switching research no canal da Associação Brasileira de Linguística na plataforma YouTube.

Margaret Deuchar está filiada ao Departamento de Linguística Teórica e Aplicada. Suas áreas de interesse são temas como code-switching (doravante CS), bilinguismo, línguas em contato, variação linguística e corpus linguístico. Os estudos da pesquisadora, juntamente com sua equipe, se concentram em três grupos de bilíngues: Galês-Inglês, Espanhol-Inglês e Galês-Espanhol. A partir dos dados obtidos com os três pares de bilíngues, Deucher avalia, por exemplo, teorias linguísticas sobre o CS a fim de comparar padrões em relação ao fenômeno em três comunidades bilíngues, além de discutir sobre CS e empréstimo linguístico ${ }^{1}$.

A professora iniciou sua fala apresentando as três perguntas que nortearam sua conferência. A primeira pergunta questiona o que é de fato CS. A segunda pergunta aborda quais são os critérios utilizados para definir CS e empréstimos linguísticos. Já a terceira pergunta questiona quais evidências existem sobre os padrões de uso de CS em comunidades de bilíngues que compartilham as mesmas línguas.

Deuchar argumenta que o CS diz respeito ao uso de mais de uma língua em um mesmo enunciado ou evento linguístico. Porém, a autora questiona se o CS é um ponto do enunciado em que a língua muda ou o CS é material resultante de uma troca? Observando os exemplos apresentados, notamos que os padrões de CS entre os bilíngues do par espanhol-inglês e do par inglês-galês são distintos. Dessa forma, observa-se que há dois tipos de CS: o intraclausal e o interclausal. O intraclausal corresponde a alternância dentro de uma mesma sentença, enquanto o interclausal diz respeito a alternância entre as sentenças. Para Deuchar, o CS é visto como a inserção de material linguístico por meio da abordagem sintática.

No caso do CS intraclausal, ou seja, inserção de itens ao longo da sentença, Myers-Scotton (2002) propõe a Matrix Language Frame (MLF). Nessa proposta, há dois fundamentos envolvidos, a Matrix Language (ML) e a Embedded Language (EL). A ML refere-se à língua que rege a sintaxe da sentença. Isto é, na fala bilíngue, haverá uma língua que será a dominante naquela situação comunicativa que estabelece quais regras morfossintáticas serão aplicadas na sentença. Dito de outra forma, a ML só permitirá que sejam inseridos itens de outra língua na sentença se for aceitável pela sintaxe da ML. Por outro lado, a EL é a língua menos ativa naquele contexto, a não dominante na situação comunicativa e que estará sujeita à ML. Cabe ressaltar que os modelos apresentados não são, a primeira vista, fáceis de serem compreendidos, porém, Deucher os apresenta de uma forma objetiva e clara, principalmente para o ouvinte que ainda não está familiarizado com o tema de CS.

1 As informações referentes às pesquisas e áreas de interesse da professora foram extraídas de https://www.languagesciences.cam.ac.uk/directory/professor-margaret-deuchar. Acesso em: 17 ago. 2020. 


\section{REVISTA DA ABRALIN}

Discutida a primeira questão da conferência, a professora inicia sua argumentação em vista da segunda pergunta, ou seja, quais são os critérios utilizados para distinguir CS e empréstimos linguísticos. Esse tópico se torna interessante e fundamental para quem pesquisa sobre o tema, visto que, até o momento, não há um modelo a ser seguido na classificação entre CS e empréstimo linguístico em questões práticas. Dito de outra forma, há na literatura como diferenciá-los, porém, em dados de fala, não há explicações suficientes sobre como podemos classificar um ou outro de forma satisfatória, o que pode dificultar as análises de dados de CS.

As questões teóricas que emergem sobre o tema são: (a) os empréstimos surgem como CS?; (b) o grau de integração linguística na língua destinatária distingue as categorias de CS e de empréstimo linguístico?; (c) a alternância e os empréstimos são atribuídos a diferentes línguas na mente do bilíngue? Além disso, há também questões práticas envolvidas, tais como: quais dados devem ser utilizados para testar a teoria de CS e como devemos marcar a identidade linguística dos empréstimos linguísticos ou de CS na transcrição de dados dessa natureza?

Deuchar questiona se todas as trocas produzidas por bilíngues são code-switching ou se há empréstimos, bem como se é possível distinguir um e outro nos dados analisados. Para responder a esses questionamentos, são apresentados exemplos de dados de bilíngues falantes de galês-inglês a fim de averiguar se as inserções são consideradas CS ou empréstimos linguísticos, conforme (1):

(1) Pan dach chi'n defnyddio wide-angle lenses Dach chi'n emphasize-io'r foreground.

Nessa sentença, o galês é considerado a ML e o inglês a EL. Como muitas palavras do inglês são aceitas como parte do vocabulário galês, os transcritores desse corpus observaram, primeiramente, o local da frase onde ocorreu a alternância de língua. Em seguida, buscaram essas palavras no dicionário galês. Se não houvesse entrada lexical para tal, então classificavam como CS. Caso a palavra aparecesse no dicionário galês, não era possível simplesmente classificá-la como CS. Dessa forma, quando uma entrada lexical aparecia no dicionário galês, os pesquisadores consideraram como um empréstimo linguístico. Entretanto, um dos problemas desse método é que muitas línguas não estão codificadas em dicionários.

Em relação ao CS de apenas um item, há duas visões divergentes na questão da integração morfossintática. Para Poplack e Meechan (1998) a troca de apenas um termo é considerada empréstimo linguístico. Já para Myers-Scotton (1993) a integração morfossintática pode ser dividida em dois tipos: a) central e b) periférica. Apenas o tipo periférico é relevante para distinguir entre CS e empréstimo. Em síntese, na segunda questão apresentada, a professora Deuchar destaca que são necessárias medidas sutis (periféricas) de integração para distinguir empréstimos e o CS, sendo que, neste último, a ML impôs a morfossintaxe da sentença.

Por fim, a última parte da fala buscou argumentar sobre a terceira questão levantada, ou seja, sobre quais são as evidências nos padrões de CS em comunidades bilíngues. Para Deuchar, como as normas de escolha de línguas são compartilhadas, deveria ser investigado se de fato as normas são compartilhadas e se são uniformes em toda a comunidade ou se variam de acordo com fatores 


\section{REVISTA DA ABRALIN}

externos, como sexo ou idade. A professora sugere que existam normas específicas da comunidade que as pessoas adquirem em termos de input linguístico.

Ao fim da conferência, a professora sumariza as respostas das três questões discutidas. A primeira diz que as alternâncias intraclausais são mais claramente definidas ao se estabelecer a morfossintáse da ML como a central da sentença. A segunda é que os empréstimos são mais integrados linguisticamente do que o CS, mas os meios de integração são sutis e podem não ser categóricos. Para encerrar, Deuchar diz que a análise baseada em dados bilíngues é vantajosa para mostrar assimetria entre a ML e a EL, porém podem existir normas comunitárias sobre a seleção da ML nas sentenças monolíngues e bilíngues.

Em suma, a autora apresentou e arguiu sobre três questionamentos importantes para compreender o fenômeno: o que é CS; como distingui-lo de empréstimos linguísticos; e sobre os padrões de CS em comunidades bilíngues. Visto que o CS é um fenômeno complexo, a fala da professora Deuchar no canal da Abralin foi clara e objetiva, apresentando diversos exemplos que auxiliam a compreender sobre o CS. Por fim, a fala proferida pela professora é um importante instrumento para aqueles que buscam conhecer sobre a área ou até mesmo se aprofundar nas pesquisas sobre o assunto.

\section{REFERÊNCIAS}

MYERS-SCOTTON, Carol. Contact Linguistics: Bilingual Encounters and Grammatical Outcomes. Oxford: Oxford University Press, 2002.

MYERS-SCOTTON, Carol. Duelling Languages: Grammatical Structure in Codeswitching. Oxford: Clarendon Press, 1993.

POPLACK, Shana; MEECHAN, Marjory. Introduction: How Languages Fit Together in Codemixing. International Journal of Bilingualism. v. 2, n. 2, p. 127-138, 1998. DOI: https://doi.org/10.1177/136700699800200201.

QUESTIONING assumptions in code-switching research. Conferência apresentada por Margaret Deuchar [s.l., s.n], 2020. 1 vídeo (1h 41min 49s). Publicado pelo canal da Associação Brasileira de Linguística. Disponível em: https://www.you-

tube.com/watch?v=CfX36mKwpsw\&ab_channel=Abralin. Acesso em: 08 jul 2020. 